\title{
I Want to Be Creative: Exploring the Role of Hedonic Contingency Theory in the Positive Mood-Cognitive Flexibility Link
}

\author{
Edward R. Hirt and Erin E. Devers \\ Indiana University Bloomington
}

\author{
Sean M. McCrea \\ University of Konstanz
}

\begin{abstract}
Three studies explored the role of hedonic contingency theory as an explanation for the link between positive mood and cognitive flexibility. Study 1 examined the determinants of activity choice for participants in happy, sad, or neutral moods. Consistent with hedonic contingency theory, happy participants weighted potential for creativity as well as the pleasantness of the task more heavily in their preference ratings. In Study 2, participants were given either a neutral or mood-threatening item generation task to perform. Results illustrated that happy participants exhibited greater cognitive flexibility in all cases; when confronted with a potentially mood-threatening task, happy participants were able to creatively transform the task so as to maintain positive mood and interest. Finally, Study 3 manipulated participants' beliefs that moods could or could not be altered. Results replicated the standard positive mood-increased cognitive flexibility effect in the nonmood-freezing condition, but no effects of mood on creativity were found in the mood-freezing condition. These studies indicate that the hedonic contingency theory may be an important contributing mechanism behind the positive mood-cognitive flexibility link.
\end{abstract}

Keywords: affect, mood effects, creativity, cognitive flexibility, hedonic contingency

\begin{abstract}
Do you ever have ideas that seem to come out of nowhere? A new thought or attitude that arrives in a flash of stunning clarity? Perhaps you have almost felt a hand on your shoulder, pointing something out, nudging you down a particular path. Or, you seemed to be in exactly the right place at the right time, and later marveled at the synchronicity of it all. You have experienced the muse
\end{abstract}

- Exploring the Muse: The Spirit of Creativity

Creativity is often characterized as an elusive, almost magical quality. It seems to spring from nowhere, whispered in one's ear by a muse or breathed into one by God. This view has been perpetuated by stories of Mozart and Coleridge authoring master works as if taking divine dictation. Indeed, numerous books, seminars, and workshops are devoted to trying to tap the muse within and unleash our untapped creative forces.

When are we most creative? Arguably, the most heavily researched predictor of creativity within the social psychological literature has been mood. One of the more robust findings has been that positive mood leads to greater creativity (Ashby, Isen, \& Turken, 1999). Positive mood states have been shown to enable individuals to categorize items, people, and situations more flex-

Edward R. Hirt and Erin E. Devers, Department of Psychological and Brain Sciences, Indiana University Bloomington; Sean M. McCrea, Department of Psychology, University of Konstanz, Konstanz, Germany.

We thank the following researchers who contributed to the studies reported in the present article: Kristin Hendrix, Gary Levine, Hugh McDonald, R. Jeffrey Melton, and Bridgett Milner. We also acknowledge the sage advice of Zakary Tormala and Duane Wegener on earlier drafts of this article.

Correspondence concerning this article should be addressed to Edward R. Hirt, Department of Psychological and Brain Sciences, Indiana University Bloomington, 1101 East 10th Street, Bloomington, IN 47405-7007. E-mail: ehirt@indiana.edu ibly and creatively (Murray, Sujan, Hirt, \& Sujan, 1990) and to see potential relatedness among unusual and atypical members of categories that can be sensibly related (Isen, Daubman, \& Nowicki, 1987; Isen, Johnson, Mertz, \& Robinson, 1985). Several possible explanations for this positive mood-creativity link have been proposed by researchers, but there has yet to be definitive research identifying the mechanism(s) behind this relationship. The present research represents an initial step in this direction, examining the possibility that hedonic contingency theory may be a contributing mechanism in the positive mood-creativity link. First, we review the different candidate explanations that have been proposed and then highlight specifically the possible role of the hedonic contingency theory.

However, before we embark on our review of these different theories of the mood-creativity relationship, it is important to clearly delineate the scope of the present investigation. Although the early results in this literature led many researchers to conclude that positive mood enhances creativity (broadly defined), several other studies have found exceptions to this general pattern, such that negative mood sometimes results in more creative performance than positive or neutral mood (cf. Gasper, 2003; George \& Zhou, 2002; Kaufmann \& Vosburg, 1997). Although a thorough review of this debate is beyond the scope of the present article, it is inappropriate to say that positive mood consistently leads to enhanced creativity, and numerous efforts have been made to clarify the nature of the mood-creativity link. A recent study by DeDreu, Bass, and Nijstad (2007) has provided a nice framework from which to accommodate these discrepant findings. DeDreu et al. noted that creativity can be a function of either cognitive flexibility or perseverance/persistence. It is interesting that they find that positive moods consistently lead to higher levels of cognitive inclusiveness and flexibility, resulting in enhanced performance on creativity tasks emphasizing these aspects. Conversely, creativity tasks that require perseverance and problem 
solving within a narrower set of cognitive categories (e.g., brainstorming/"deep exploration" tasks, cf. Rietzschel, Nijstad, \& Stroebe, in press) are facilitated by negative moods. Given this distinction, the scope of the present research is to investigate explanations for the robust facilitative effects of positive mood on cognitive flexibility, an area in which the literature has demonstrated consistently that positive mood tends to facilitate greater fluency and originality. Indeed, the extent to which the mechanisms elucidated in this article apply to other facets of creativity, such as persistence and perseverance, is a question that we return to in the General Discussion section.

\section{Mood-Congruent Retrieval}

Three main explanations have been offered for the positive mood-cognitive flexibility link. The first is mood-congruent retrieval. This view contends that positive affect serves as a retrieval cue for positive material in memory (Isen, Shalker, Clark, \& Karp, 1978; Teasdale \& Fogarty, 1979; Teasdale \& Russell, 1983). Isen and her colleagues (1985) have argued that positive material is more extensive and diverse than other material in memory so that a more "complex cognitive context" is available when a person is feeling happy. Such a complex cognitive context may lead to diverse and multiple interpretations and organizations of material in memory, features essential to cognitive flexibility. Negative affect, however, activates significantly less information, making it less likely that innovative combinations will be generated simply because there is less information to work with. Indeed, differences in the content of what information is brought to mind have been shown to have important implications for a broad range of judgments, evaluations, and expectations, including the novelty or creativity of associations (e.g., Isen et al., 1985; Isen \& Shalker, 1982; Kahn \& Isen, 1993; Kraiger, Billings, \& Isen, 1989).

\section{Cognitive Tuning Model}

Schwartz's (1990) cognitive tuning model offers a second explanation for the positive affect-cognitive flexibility link. The cognitive tuning hypothesis derives from the evolutionary significance of mood to an organism. According to Schwarz, moods convey important information to the organism about the nature of the current environment. Negative moods indicate that the current situation is problematic (e.g., danger is present, needs exist that must be addressed) and motivate action designed to alleviate or eliminate the problem. In contrast, positive moods signal that the current situation is safe and satisfactory and that no further action is necessary (Schwarz, 1994). An important corollary to this model is that moods invoke distinct processing styles. Negative moods are associated with a more effortful, analytic style of information processing, whereas positive moods are associated with a more carefree, heuristic style of information processing. Indeed, there is a great deal of evidence that supports the predictions of the cognitive tuning model. Individuals in negative moods have been shown to perform better at tasks that require systematic or analytic problem solving and rely less on shortcuts such as heuristics or stereotypes as compared with individuals in positive moods (Bless, Bohner, Schwarz, \& Strack, 1990; Bodenhausen, 1993; Sinclair, 1988; Sinclair \& Mark, 1995; Worth \& Mackie, 1987).
These differences in processing styles have important implications for cognitive flexibility. Individuals in a negative mood focus their attention narrowly on the problem at hand. Those in a positive mood, however, are free to be playful and explore new ideas. The broadening of scope associated with positive mood presumably allows individuals to access a diverse range of ideas that can be applied to the situation more flexibly and to take the kind of risks that are associated with creative solutions (Schwarz, 1994).

\section{Mood as Input}

A third view commonly used to explain the possible mechanism underlying the effect of mood on cognitive flexibility is the moodas-input view. The mood-as-input model, like the cognitive tuning model, proposes that moods provide people with information (Clore, Schwarz, \& Conway, 1994; Schwarz \& Clore, 1988). However, according to this model, moods do not have universal (i.e., main) effects on information processing; instead, the significance and consequences of the information provided by one's current mood state depend on the context (Bransford \& Johnson, 1972; Martin \& Stoner, 1996). The notion underlying this contextdependent view of mood is that the implications of positive moods are quite different, for instance, when assessing one's enjoyment of a task as opposed to one's satisfaction with the quality of one's performance.

In an impressive body of research, Martin and his colleagues (Hirt, Melton, McDonald, \& Harackiewicz, 1996; Martin, Ward, Achee, \& Wyer, 1993; Sanna, Turley, \& Mark, 1996) have manipulated the stop rules participants use for deciding when to finish working on a task. Some participants were instructed to stop when they felt they had enough information to render a decision (a performance-based stop rule); other participants were instructed to stop when they no longer enjoyed the task (an enjoyment-based stop rule). According to the mood-as-input model, participants in positive moods should evaluate the quality and sufficiency of their performance more favorably than participants in negative moods, based on the "feelings as information" heuristic (Schwarz \& Clore, 1983, 1988). As a result, when given a performance-based stop rule, positive mood individuals should stop earlier than those in a negative mood. Conversely, participants in positive moods should infer that they are enjoying the task more than participants in negative moods; thus, when given an enjoyment-based stop rule, individuals in a positive mood should persist at the task longer than individuals in a negative mood (Martin \& Stoner, 1996).

The predictions derived from the mood-as-input model have received strong empirical support (Hirt et al., 1996; Martin et al., 1993). However, these effects were observed on quantitative measures of task performance, such as time spent on the task and number of items generated. Nonetheless, Martin and Stoner (1996) extended the mood-as-input model directly to creativity. In their research, participants were placed in either a happy or sad mood and then asked to perform a word association task (cf. Isen et al., 1985 ) in which they were presented with a sequence of common words and were given $3 \mathrm{~s}$ to generate the first word that came to mind. After their initial response, participants were given the opportunity to generate a different response if they so desired. Martin and Stoner then manipulated the decision rule participants were to use in determining how to respond. One group was instructed to ask themselves "Can I come up with a better re- 
sponse?" The other group was instructed to ask themselves "Is my initial response a good one?" The results conformed well with the predictions of the mood-as-input model. Participants in a happy mood given the "Can I come up with a better response?" rule were more likely to generate a second response than were sad participants, for their happy mood led them to be optimistic about their ability to generate a more creative response. Conversely, participants in a happy mood given the "Is my initial response a good one?" were less likely to generate a second response than were sad participants because their happy mood led them to judge their initial response more favorably. On the basis of these findings, Martin and Stoner argued that the effects of positive mood on creativity are context dependent and can be explained in terms of the mood-as-input model.

\section{A Critical Test}

It is important to note, however, that the effects observed by Martin and Stoner (1996) reflected participants' subjective perceptions of their own creativity, not the actual creativity of their responses per se. Indeed, when they examined the creativity of participants' responses across the various conditions, they found no differences. ${ }^{1}$ Moreover, Hirt et al.'s (1996) study, mentioned earlier, examined both qualitative (i.e., cognitive flexibility of participants' responses) as well as quantitative measures of performance (e.g., time spent, number generated) and found a different pattern of results on each. For the quantitative measures, they found significant Mood $\times$ Stop Rule interactions, consistent with the mood-as-input model. In addition, mediational analyses revealed that participants' pretask interest partially mediated the effects of mood and stop rule on these measures of task performance: Participants spent more time and generated more responses when they anticipated the task as more fun and interesting. However, a distinctly different pattern emerged for cognitive flexibility. No Mood $\times$ Stop Rule interaction was obtained; only a main effect of mood was observed, such that individuals in a positive mood were more creative than negative or neutral mood participants regardless of stop rule. Mediational analyses revealed that pretask interest did not mediate the effects of mood on cognitive flexibility; instead, cognitive flexibility was found to partially mediate the effects of mood on posttask interest. That is, being creative at the task facilitated greater posttask interest. On the basis of these results, Hirt et al. (1996) suggested the possibility that different mechanisms may account for the effects of mood on qualitative (cognitive flexibility) as opposed to quantitative aspects of performance.

To further demonstrate this notion, Hirt, Levine, McDonald, Melton, and Martin (1997) sought a critical test of the mood-asinput predictions. An important premise of the mood-as-input view (or the more general "feelings as information" view proposed by Schwarz and Clore, 1983, 1988) is that individuals "may use their current feelings as a basis of judgment unless the diagnostic value of their feelings for the judgment at hand is called into question" (Schwarz \& Bohner, 1996, p. 127). A number of studies have demonstrated that cueing participants as to the source of their mood eliminates mood effects on a variety of judgments (cf. Clore et al., 1994). Thus, Hirt et al. (1997) posited that providing participants with a mood source cue should eliminate the Mood $\times$ Stop Rule interactions obtained on quantitative measures of per- formance. Participants cued to the actual source of their mood would no longer use their current mood as a basis for answering the stop rule questions. However, an examination of the effects of the mood source cue on the cognitive flexibility of responses provided a critical test of mechanism. If Martin and Stoner's (1996) mood-as-input account were correct, then the effects of mood on cognitive flexibility should be eliminated when participants are given a mood source cue. Alternatively, if Hirt et al. (1996) were correct and a different mechanism underlies the effects of mood on cognitive flexibility, then the mood source cue should have no effect on the creativity of responses.

Indeed, the results of Hirt et al. (1997) provided strong support for the multiple mechanism view. Although the mood source cue did effectively eliminate the Mood $\times$ Stop Rule interactions on the quantitative measures, it had no effect on the cognitive flexibility of responses. The main effect of mood on cognitive flexibility remained even when participants were given the mood source cue, rendering a mood-as-input account for the positive moodcognitive flexibility link implausible. On the basis of these results, Hirt et al. (1997) concluded that a different mechanism must be responsible for the facilitating effects of positive mood on cognitive flexibility.

\section{The Hedonic Contingency Theory}

Although the Hirt et al. (1997) research effectively ruled out a mood-as-input (or more generally, a "feelings as information") account for the positive mood-cognitive flexibility link, it could not distinguish among other candidate mechanisms. A moodcongruent retrieval account certainly remained viable. Nonetheless, Hirt et al. (1997) proposed an alternative mechanism derived from a mood management perspective, namely, a hedonic contingency theory account (Wegener \& Petty, 1994, 1996). According to this theory, happy individuals are interested in sustaining their positive mood state, whereas sad individuals are interested in mood repair (cf. Cialdini \& Kenrick, 1976). The key prediction of this model is that because there are more potentially moodsabotaging tasks for individuals in happy moods, happy individuals must be even more vigilant about the hedonic qualities of tasks they contemplate performing than sad individuals. Thus, hedonic contingency theory posits that happy individuals scrutinize the hedonic consequences of a particular action more carefully than individuals in other moods and will only choose actions that will either maintain or improve their positive mood. In contrast, those in sad or neutral moods do not need to scrutinize hedonic consequences to the same degree because there are many more activities that will maintain or improve their mood.

\footnotetext{
${ }^{1}$ The astute reader may note that we use the broader term creativity rather than cognitive flexibility to refer to the findings of the Martin and Stoner (1996) work. We do this intentionally in order to highlight the ambiguity inherent in their measure. It is unclear in their work whether their responses reflect cognitive flexibility, persistence, or some combination of the two. Indeed, the fact that sad participants were more likely to persist at the task and generate a second response to the "Is my initial response a good one?" rule seems entirely consistent with the DeDreu et al. (2007) framework. Moreover, given that Martin and Stoner found no differences in the actual cognitive flexibility of responses in their work, one cannot draw any definitive conclusions regarding the role of mood on cognitive flexibility per se from this work.
} 
How would hedonic contingency theory explain the positive mood-cognitive flexibility link? The theory would maintain that happy individuals in the service of mood management might deliberately set out to generate creative responses as a means of making the task more fun and interesting, thereby maintaining or enhancing their positive mood. Indeed, Wegener and Petty (2001) specifically argued that,

if, consistent with our hedonic contingency perspective, happy people are more spontaneously concerned with feeling good during and after the task, they might be more likely to engage in the task in a manner that makes the task more enjoyable. Thus, it could be that happy people generate more creative responses (in part) as an attempt to enjoy the task more. (p. 197)

Thus, this perspective would argue that the enhanced cognitive flexibility of happy individuals derives from their strategic efforts to sustain their happy mood.

Is it the case that people strategically attempt to be creative for this purpose? To begin to address this question, we first conducted a pretest in which we asked 83 participants about their implicit theories about the relationship between mood and creative performance. First, participants were asked to report on how likely it is that they will participate in a list of specific activities when in a positive mood. Next, participants answered the same questions regarding how likely it is that they will participate in these same specific activities when in a negative mood. Among the activities listed were activities that previous participants had rated as creative as well as activities that had not been rated as creative. The pretest data indicated that the tasks that were ranked as most creative were the same tasks participants indicated that they were likely to do when in a positive mood, but not when in a negative mood. A second set of questions on the pretest asked participants in which of the following moods they are most likely to be creative: annoyed, happy, depressed, miserable, satisfied, gloomy, pleased, sad, delighted, content, frustrated, and glad. Of the 83 participants, 76 endorsed one of the positively valenced moods (45 of them endorsed happy specifically, with 31 choosing one of the other positively valenced moods like satisfied, pleased, delighted, or glad).

Given these pretest data, it is clear that participants are aware that they are more attracted to creative tasks when in a positive than in a negative mood. However, these data do not speak to the question of whether people in happy moods explicitly seek to be creative in order to satisfy their mood management goals. Thus, the present research was designed to address this question.

Although there is no evidence we are aware of to date that explicitly tests this hypothesis, there is a substantial amount of research supporting the hedonic contingency theory more generally. Evidence from a number of domains, including choices regarding entertainment (Zillmann, 1988), recall of past behaviors (Parrott \& Sabini, 1990), thought suppression (Wenzlaff, Wegner, \& Roper, 1988), scrutiny given to persuasive messages (Petty, Gleicher, \& Baker, 1991; Smith \& Shaffer, 1991; Worth \& Mackie, 1987), and effort people put into decision-making activities (Isen \& Means, 1983), illustrate that people learn what behaviors induce a positive mood quite readily and are more likely to repeat behaviors that they believe will produce or sustain positive feelings when in a happy mood. Most notably, in the area of helping, several studies show that those who feel good exhibit increased helpfulness when the helping task is inherently pleasant but tend to help less than others when the act of helping is distasteful (Forest, Clark, Mills, \& Isen, 1979; Harada, 1983; Isen \& Levin, 1972; Isen \& Simmonds, 1978).

Wegener and Petty's (1994) original research used a selective exposure paradigm in which participants ranked their choice of videos after being induced into a happy, sad, or neutral mood. Participants were told that these videos had been rated previously by a large number of college students and were given the average ratings on three dimensions: how agreeable/useful, how happy, and how interesting/exciting the video was to students. They found that happy participants were more likely to use the happy dimension in determining their ranking of the candidate videos than were those in a sad or neutral mood. These results indicate directly that happy individuals are more likely to choose activities strategically on the basis of their hedonic consequences than individuals in other mood states.

The present research represents an initial attempt to explore the viability of a hedonic contingency account for the positive moodcognitive flexibility link. If this view is correct, then happy individuals should only demonstrate enhanced cognitive flexibility on tasks for which it is clear that being creative will serve to sustain or enhance their happy mood. To the extent that being creative does not serve these mood management goals, the positive moodcognitive flexibility relationship should be severed. Three studies are presented that test these predictions explicitly.

\section{Study 1}

Study 1 addressed whether happy individuals choose tasks strategically on the basis of their potential for creativity. In Study 1, we used the selective exposure paradigm similar to Wegener and Petty (1994), with a few notable exceptions. As in Wegener and Petty (1994), participants were asked to rate their preferences from among a set of possible tasks. However, instead of providing participants with ratings made by other college students of each option, participants in Study 1 first made their own subjective ratings of the set of stimuli prior to making their preference ratings. In this way, we could assess the extent to which participants' own subjective perceptions of the task affected their preference ratings.

Study 1 participants were given a range of different categories that could be used for a generation task. We chose to use a category generation task for several reasons. First, these sorts of tasks have been commonly used in the literature to assess divergent thinking and cognitive flexibility. Furthermore, these same tasks are included as subtests in most standard tests of creativity (e.g., the Torrance Test of Creative Thinking [TTCT]; Torrance \& Ball, 1984) and have been shown to account for nearly $50 \%$ of the variance in scores of creative achievement, more than three times as much as IQ (Carson, Peterson, \& Higgins, 2003; Plucker, 1999). Finally, scores on such tests of divergent thinking are not correlated with intelligence or skill level, avoiding the potential pitfalls of other creativity tasks that require domain-specific skills or knowledge. Thus, we felt the use of category generation tasks provided us with the best opportunity to test our predictions about a positive mood-cognitive flexibility link.

These different categories were selected on the basis of a pretest to provide diversity in several dimensions: category valence, interest level, ease/difficulty, knowledge, and potential for creativity. 
Participants were first asked to rate the various tasks on all five of these dimensions. Then, following a mood induction procedure, participants went back to the list of tasks and rated their preference for these same tasks. From these data, we computed the average weight given to each of the target dimensions in their preference ratings.

Hedonic contingency theory predicts that happy individuals will be particularly vigilant of the hedonic qualities of potential tasks and will strongly prefer tasks that will maintain or enhance their current mood. Thus, consistent with hedonic contingency theory, we expected that happy participants would be particularly attentive (and give greater weight) to the valence of the task relative to those in other mood states. However, we were also interested in whether happy participants would be more motivated to select tasks on the basis of their potential for creativity. If indeed it is the case that happy people are more cognitively flexible in the service of mood management concerns, then we would expect that individuals in happy mood would also weight potential for creativity more in their task preference ratings than individuals in other mood states.

\section{Method}

Participants. Participants were 92 introductory psychology students at Indiana University Bloomington. They participated in partial fulfillment of a course requirement. Participants were tested individually.

Procedure. After completing the informed consent form, participants were told that they would be participating in two brief experiments. For the first "experiment," participants were given a questionnaire packet. The first experimenter explained that for several years, we have been doing experiments on "the things that come to people's minds," specifically giving participants a category of objects and asking them to list as many members of that category as they can think of. The experimenter explained that, in this study, participants would be asked to perform a similar category generation task. On the first page of the questionnaire, participants were shown a list of 24 examples of the types of categories that previous participants had ostensibly been given and asked to spend a few moments looking over the list.

Next, the experimenter told participants that we first wanted to get some information from them about their thoughts and feelings about these different tasks. All participants were then given five different rating tasks to perform; the order of these five tasks was counterbalanced in the questionnaire packets. Specifically, participants were asked to rate each of the tasks listed (a) in terms of "how pleasant or unpleasant it would be for you to think about the following category of objects" on a -5 (very unpleasant) to +5 (very pleasant) scale; (b) "how interesting you personally would find the task" on a 1 (very dull and uninteresting) to 11 (very interesting) scale; (c) "how easy or difficult the task would be for you personally to do" on a 1 (very difficult) to 11 (very easy) scale; (d) "how much knowledge you personally would have about that category of objects" on a 1 (very little) to 11 (very much) scale; and (e) "how much the task calls for or allows for creativity in responding" on a 1 (does not allow people to be creative) to 11 (strongly encourages people to be creative) scale. Each rating task appeared on a separate page of the questionnaire. The meaning of the different points of the scale was explained, and participants were instructed to try to use the full range of the scale in their ratings. When participants finished the booklet, it was collected by the first experimenter, who explained that this concluded the first part of the study and that they would now do a short second study before completing Part 2.

Participants then were moved into a cubicle by a second experimenter. This experimenter explained that this second "experiment" asked for their assistance in rating a series of film clips (cf. Hirt et al., 1997). Participants were randomly assigned to one of three sets of film clips, previously shown to induce happy, sad, or neutral feelings. As in Hirt et al. (1997), participants watched three film clips, each approximately $4 \mathrm{~min}$ in length. Participants in all three mood conditions first saw a car chase scene from the movie Bullitt (Relyea \& Yates, 1968). This arousing but affectively neutral clip was included primarily to reduce participants' suspicion about the true purpose of the mood induction. Participants in the happy mood condition then viewed humorous clips from the movies Pretty Woman (Ziskin \& Marshall, 1990) and Mrs. Doubtfire (Rushton \& Columbus, 1993), whereas participants in the sad mood condition viewed somber clips from the movies Ordinary People (Schwary \& Redford, 1981) and Sophie's Choice (Stanger $\&$ Paluka, 1982). Participants in the neutral mood condition viewed two documentary clips, one entitled Powers of Ten (Eames $\&$ Eames, 1977) and the other about the behavior of African lions in the wild. When they completed their rating of the final film clip, participants rated their current mood on a set of 14 Multiple Affect Adjective Check List-type adjectives (Zuckerman \& Lubin, 1985; good, happy, miserable, cheerful, depressed, calm, sad, relaxed, delighted, anxious, energetic, aroused, tense, and excited) using a 1 (not at all) to 5 (very strongly) scale.

At this point, the first experimenter returned and gave participants the final ratings booklet. The first page of this booklet explained that while previous studies had assigned participants to one of these categories, participants in the present study would have a choice as to which of these tasks they would like to do. Participants were then given the list of 24 categories again and asked to rate each task in terms of "how much you would like to do it" on a 1 (the task that I would least like to do) to 11 (the task that I would most like to do) scale. Again, the experimenter explained the rating scale and encouraged participants to use the entire range of the scale. After completing these ratings, participants were instructed to choose which category they would most like to do. Finally, they were probed for suspicion and subsequently debriefed. At this point, participants were asked to rate to what extent each of the five dimensions influenced their choice of task on a 1 (not at all) to 7 (very much) scale.

\section{Results}

Mood manipulation check. A factor analysis performed on the mood check revealed three factors accounting for $66.8 \%$ of the variance. Factor $1(\alpha=.85)$ consisted of five items: energetic, aroused, excited, calm (reverse scored), and relaxed (reverse scored). An analysis of variance (ANOVA) on Factor 1 scores revealed a significant mood main effect, $F(2,85)=5.80, p<.01$ Participants in the happy mood condition were more aroused $(M=$ 12.6) than both sad $(M=9.4)$ or neutral $(M=10.3)$ individuals (both $t \mathrm{~s}>2.2, p \mathrm{~s}<.05)$. Factor $2(\alpha=.81)$ consisted of four items: cheerful, delighted, good, and happy. An ANOVA on Factor 2 scores also revealed a significant mood main effect, $F(2$, 
$85)=7.23, p=.001$. Happy individuals expressed more positive affect $(M=14.9)$ than either sad $(M=12.6)$ or neutral $(M=12.1)$ individuals (both $t \mathrm{~s}>2.8, p \mathrm{~s}<.01)$. Finally, Factor $3(\alpha=.86)$ consisted of three items: miserable, depressed, and sad. An ANOVA on Factor 3 scores showed a mood main effect, $F(2$, $85)=4.58, p<.02$, with sad individuals $(M=5.2)$ expressing greater negative affect than either happy $(M=3.8)$ or neutral $(M=4.0)$ individuals (both $t \mathrm{~s}>2.2, p \mathrm{~s}<.05)$. Thus, it appears our mood manipulation was quite successful in inducing the desired mood.

Weighting of dimensions. Our primary hypothesis concerned differences in the relative weighting of the pleasantness and potential for creativity dimensions across mood conditions. Hedonic contingency theory predicts that happy individuals would give greater weight to the pleasantness dimension relative to sad or neutral individuals, consistent with their greater need to scrutinize the hedonic consequences of potential activities. We believed that happy individuals might also weight the potential for creativity dimension more strongly as well because our hedonic contingency account posits that being creative is one way to maintain and enhance one's positive mood. To examine this question, we conducted regression analyses for each individual participant, predicting desirability ratings from ratings on the five predictor dimensions (pleasantness, interest, difficulty, knowledge, potential for creativity). The beta weights for each of the five predictor dimensions were computed for each participant (as well as the overall $R^{2}$ for the regression equation). These data are presented in Table 1.

We next conducted a repeated measures ANOVA, with mood condition as the between-subjects variable and the five dimensions as the repeated measures variable. Because arousal (Factor 1) varied across mood conditions, we treated arousal as a covariate in these analyses to ensure that any differences obtained were the result of valence of mood state independent of differences in level of arousal. This analysis revealed a significant effect of dimension, $F(4,80)=9.08, p<.001$. Overall, participants weighted pleasantness $(M=.49)$ more than any other dimension, followed by interest $(M=.24)$, difficulty $(M=.13)$, potential for creativity $(M=.12)$, and knowledge $(M=.09)$. This effect was qualified, however, by a Mood $\times$ Dimension interaction, $F(8,160)=8.57$, $p<.001$. To examine the nature of this interaction, separate univariate ANOVAs were conducted on each of the individual dimensions. Consistent with our predictions, an ANOVA on the mean beta weight given to pleasantness varied across mood conditions, $F(2,88)=32.83, p<.001$. Happy individuals $(M=.75)$ weighted pleasantness significantly more than sad individuals $(M=.41), t(61)=5.67, p<.001$; both happy and sad individuals weighted pleasantness more than neutral mood individuals $(M=$ .27 ; both $t \mathrm{~s}>2.2, p \mathrm{~s}<.05){ }^{2}$ This result nicely parallels the findings of Wegener and Petty (1994), albeit using subjective ratings of task pleasantness as opposed to consensus ratings ostensibly provided by others. More important, we also found a significant mood effect on the weight given to potential for creativity, $F(2,83)=3.71, p=.029$. Happy individuals weighted potential for creativity significantly more $(M=.17)$ than either sad $(M=.09)$ or neutral $(M=.09)$ individuals (both $t \mathrm{~s}>2.3, p \mathrm{~s}<$ $.05)$. Thus, it appears that happy individuals also consider the potential for creativity in addition to overall task pleasantness more in their task choice.
Table 1

Study 1: Mean Beta Weights for Variables Predicting Desirability Ratings

\begin{tabular}{lccc}
\hline & \multicolumn{3}{c}{ Mood condition } \\
\cline { 2 - 4 } \multicolumn{1}{c}{ Variable } & Happy & Neutral & Sad \\
\hline Pleasantness & $0.75_{\mathrm{a}}$ & $0.27_{\mathrm{c}}$ & $0.41_{\mathrm{b}}$ \\
Interest & $0.10_{\mathrm{b}}$ & $0.36_{\mathrm{a}}$ & $0.29_{\mathrm{a}}$ \\
Difficulty & $0.02_{\mathrm{b}}$ & $0.17_{\mathrm{a}}$ & $0.20_{\mathrm{a}}$ \\
Knowledge & $0.09_{\mathrm{a}}$ & $0.06_{\mathrm{a}}$ & $0.11_{\mathrm{a}}$ \\
Potential for creativity & $0.17_{\mathrm{a}}$ & $0.09_{\mathrm{b}}$ & $0.09_{\mathrm{b}}$ \\
& & & \\
Overall $R^{2}$ & $0.87_{\mathrm{a}}$ & $0.74_{\mathrm{b}}$ & $0.77_{\mathrm{b}}$ \\
\hline
\end{tabular}

Note. Means not sharing a common subscript differ significantly at $p<$ .05 .

Analyses conducted on the other three dimensions revealed mood effects on the weights given to interest, $F(2,83)=8.85, p<$ .001 , and difficulty, $F(2,83)=8.58, p<.001$. Happy individuals weighted interest $(M=.10)$ and difficulty $(M=.02)$ significantly less than both sad (interest $M=.29$; difficulty $M=.20$ ) and neutral mood individuals (interest $M=.36$; difficulty $M=.17$; all $t \mathrm{~s}>3.0, p \mathrm{~s}<.01$ ). Sad and neutral mood conditions did not differ on either of these dimensions. No significant differences in mood were obtained on the weightings given to knowledge $(F<1, n s)$.

We also computed the mean overall $R^{2}$ for the prediction of desirability ratings from the five dimensions. An ANOVA performed on this measure also revealed a significant mood effect, $F(2,83)=8.81, p<.001$. A greater amount of variance was accounted for in the prediction of desirability ratings from these five dimensions in the happy mood condition $(M=.87)$ than in the $\operatorname{sad}(M=.77)$ or neutral mood conditions $(M=.74$; both $t \mathrm{~s}>3.0$, $p s<.001)$.

Ratings and choice of tasks. The interested reader may want to know whether there were any differences in the ratings given to specific tasks or the actual choices made by individuals in the various mood conditions. We subjected the desirability ratings of the 24 tasks to a factor analysis. This analysis revealed three significant factors that accounted for $68.4 \%$ of the variance. The first factor consisted of eight negatively valenced tasks (causes of death, contemporary social problems, disgusting things, reasons why relationships break up, stressful life events, things that irritate and annoy people, things that make people depressed, and tragic events) and had good reliability $(\alpha=.88)$. The second factor included nine tasks (ways to spend lottery money, vacation spots, pets, desserts, colors, articles of clothing, items of furniture, occupations, and modes of transportation) and had moderate reliabil-

\footnotetext{
${ }^{2}$ The reader may be curious as to which component of the mood manipulation might be accounting for these effects. Additional analyses including all three dimensions of the mood manipulation check (arousal, positive affect, negative affect) as predictor variables revealed that the positive affect factor accounted for all of the significant effects of the mood manipulation on the dependent variables examined in this study. Thus, consistent with hedonic contingency theory, the degree to which the individual was experiencing positive affect led to differential weighting of pleasantness as opposed to other factors in determining task choice. More important, arousal did not predict weightings of any of the five dimensions.
} 
ity $(\alpha=.75)$. The third and final factor consisted of the final seven tasks (TV shows, favorite entertainers, games, hobbies, famous inventions, musical instruments, and things that begin with the letter $M)$ and had moderate reliability $(\alpha=.71)$. Factor scores were computed for each participant and analyzed using an analysis of covariance (treating arousal as a covariate).

A significant effect of mood was found on the first factor (negatively valenced tasks), $F(2,84)=14.21, p<.001$. Happy individuals rated these tasks less desirable $(M=22.6)$ than did sad individuals $(M=28.9), t(62)=2.68, p<.01$; both happy and sad individuals rated them as less desirable than did neutral mood individuals $(M=38.2$; both $t \mathrm{~s}>3.0, p \mathrm{~s}<.01)$. No effects of mood were obtained for either of the other two factors (both $F \mathrm{~s}<$ $1.6, n s)$. Thus, it is only for the negatively valenced tasks that mood leads to differential evaluation of the desirability of these tasks.

An examination of the specific tasks chosen by participants revealed that nearly everyone chose tasks from Factors 2 and 3. No differences were obtained in the task chosen as a function of mood condition. The majority of participants chose either ways to spend lottery money (18/92), TV shows (15/92), vacation spots (13/92), or pets $(8 / 92)$.

Awareness. One might question whether these differences in the weightings of these various dimensions across mood conditions reflect a conscious decision. At debriefing, we asked participants to rate to what extent each of the five dimensions influenced their choice of tasks. A repeated measures ANOVA on these subjective ratings revealed a main effect of rated dimension, $F(4$, $80)=10.12, p<.001$, but no interaction with mood. It is interesting that participants overall rated the extent to which they relied on knowledge $(M=5.70)$, interest $(M=5.48)$, and difficulty $(M=5.43)$ much greater than the extent to which they relied on pleasantness $(M=4.65)$ or potential for creativity $(M=4.64)$. Moreover, the correlations between participants' subjective assessments of the extent to which they relied on each of these dimensions and the beta weights derived from their actual ratings were all nonsignificant ( $r$ s ranging from -.04 to .15). Thus, it does not appear as though participants have conscious awareness of their differential weighting of these dimensions in their preferences (cf. Nisbett \& Wilson, 1977).

\section{Discussion}

The results of Study 1 provide clear evidence in support of the predictions of hedonic contingency theory. Using participants' own subjective ratings rather than externally provided ones, we found that, consistent with past research (Wegener \& Petty, 1994), participants in happy moods gave significantly greater weight to the pleasantness dimension relative to participants in sad or neutral moods. Conversely, happy participants gave correspondingly less weight to the interest level and difficulty dimensions relative to those in other mood states. It is of interest that the heavy reliance of happy participants on the predictor of pleasantness resulted in a significantly greater overall $R^{2}$ relative to participants in these other moods, attesting to the importance placed on this factor in task preference ratings.

The data from Study 1 also revealed that, consistent with hedonic contingency theory, happy participants showed a greater aversion to negatively valenced tasks than did participants in the sad- and neutral mood conditions. Thus, it is clear that happy participants would be unlikely to choose negatively valenced (and potentially mood-threatening) tasks when there were more positively (or neutrally) valenced tasks available.

The most intriguing aspect of the Study 1 results was the fact that happy participants showed a greater tendency to weight the potential for creativity dimension than did sad or neutral mood participants. Indeed, over and above their primary concerns with the hedonic features of the task (i.e., pleasantness), happy participants also chose tasks on the basis of whether they subjectively perceived the task as having the potential for creative responding more so than did participants in other mood states. ${ }^{3}$ Thus, it appears that a happy mood does engender a greater attraction to tasks that afford one the potential to be creative. This finding is clearly consistent with our hedonic contingency explanation for the positive mood-creativity link, suggesting that happy individuals strategically select tasks with potential for creativity.

Although the results from Study 1 provide some nice initial support for our hedonic contingency account for the positive mood-cognitive flexibility link, we must acknowledge that the data do not speak to the motivation underlying the desire to select tasks with potential for creativity. Is it the case that happy individuals choose creative tasks because by being creative on these tasks, they can maintain or enhance their current mood? Moreover, Study 1 is limited by the fact that we focused exclusively on task choice; it remains to be seen whether happy participants actually perform more creatively on these tasks they perceive to have greater potential for creativity. Indeed, the past studies in which the positive mood-cognitive flexibility link have been examined have routinely assigned participants tasks to perform and have demonstrated that happy individuals perform more creatively than individuals in other mood states. Our hedonic contingency account would predict that happy participants perform more creatively strategically in the service of mood management motives. Thus, in Study 2, we turned our attention to an assessment of the actual cognitive flexibility of performance rather than task choice. Specifically, Study 2 sought to explore the extent to which hedonic contingency concerns mediate differences in the actual creativity of performance of participants in different mood states.

\section{Study 2}

In many situations, we do not have the luxury of choosing the tasks we perform. Thus, an important question that our hedonic contingency account must address is whether these effects only occur when participants are given a positively valenced (i.e., hedonically pleasant) task to perform. Indeed, one critique often raised about the positive mood-cognitive flexibility literature more generally is that the creativity tasks that participants have been asked to perform tend to be enjoyable (or at worst, neutral)

\footnotetext{
${ }^{3}$ The reader may be interested to know that the overall correlation between ratings of pleasantness and potential for creativity in Study 1 was $r(91)=.09, n s$. However, the magnitude of this correlation varied as a function of mood condition. In the positive-mood condition, pleasantness and creativity were strongly correlated, $r(33)=.63, p<.001$, but not in the neutral, $r(28)=.08, n s$, or negative-mood conditions, $r(30)=.00, n s$. Thus, it appears that only those in positive mood states draw the connection between potential for creativity and pleasantness/enjoyment.
} 
tasks. What would happen if participants had no choice and were simply assigned a negatively valenced and potentially moodthreatening task to perform? What effects would this have on the cognitive flexibility of responses by happy participants?

To date, the hedonic contingency literature has focused almost exclusively on task choice, not on task performance in situations in which individuals are confronted with tasks of different valence. In such situations, we hypothesize one of two potential outcomes. The first we label the selectivity hypothesis. This hypothesis predicts that in the service of mood management concerns, happy participants would withdraw effort and disengage from performing a potentially mood-threatening task; such a hypothesis would predict lower creativity for happy participants when confronted with a negatively valenced as opposed to neutral or positively valenced task. However, we considered a second hypothesis, which we call the transformation hypothesis. Recall that Wegener and Petty (2001) posited that happy participants "might be more likely to engage in the task in a manner that makes the task more enjoyable" (p. 197). This hypothesis argues that happy participants, if forced to engage in a potentially moodthreatening task, might actively attempt to transform the task into something less mood threatening, allowing them to sustain their positive feelings. Indeed, past research by Sansone, Weir, Harpster, and Morgan (1992) has demonstrated that individuals confronted with a dull or boring task can engage in interest-enhancing strategies to transform the activity into something more interesting and positive to perform. Thus, their research demonstrates that when motivated to do so, people demonstrate the ability to strategically transform a task into something less boring and tedious. Because hedonic contingency theory argues that the mood management concerns of those in a positive mood are more powerful than those in other mood states, our transformation hypothesis predicts that happy participants in particular might be motivated to strategically use creativity as a means of transforming the task. That is, by being creative, they can sustain or enhance their happy mood independent of the (potentially moodthreatening) features of the task itself. ${ }^{4}$

In order to test these predictions, Study 2 replicated the earlier Hirt et al. (1997) study but varied the valence of the generation task. Participants were asked to generate either modes of transportation (a hedonically neutral task, used previously in Hirt et al., 1997, for which reliable mood effects were obtained) or causes of death (a hedonically unpleasant task, cf. Study 1).

\section{Method}

Participants. Participants were 210 introductory psychology students (87 men, 123 women) at Indiana University Bloomington. They participated in partial fulfillment of a course requirement.

Procedure. Participants were tested in small groups of up to 3, and groups were randomly assigned to conditions. Multiple sessions of each condition were run to minimize group and session effects. When participants entered the lab, they were greeted by a male experimenter who ushered them into an individual cubicle. After completing the consent form, participants were told they would be participating in several different tasks, the first of which involved rating films.

The mood induction paralleled that of Study 1. After each film clip, participants answered several questions assessing their evaluation of the clip, in line with the cover story. After rating all three clips, participants completed a mood manipulation check, which asked them to assess, on a scale from 1 (not at all) to 7 (very much), to what degree a particular adjective fit their current mood. The adjectives included the words annoyed, happy, depressed, miserable, satisfied, gloomy, pleased, sad, delighted, content, frustrated, and glad.

After completing the mood measure, participants were given a brief 1.5-min filler task of drawing a map of campus (cf. Martin et al., 1993). The purpose of this task was ostensibly to "examine the way people represent in memory information about their environment," but in reality served as a psychological break between the mood induction and generation task.

After completing the map drawing task, the experimenter informed participants that the next study examined "the things that spontaneously come to people's minds." Participants would be given a category of objects and asked to think about and list members of that category. The instructions emphasized that there were no right or wrong answers and that "the examples you generate can be as commonplace or as creative and out of the ordinary as you like." After receiving these instructions, participants were told that they would be listing either "causes of death" or "modes of transportation." Before completing the listing task, participants were given a five-item pretask interest measure, which asked them to predict how interesting and enjoyable they thought the task would be. Next, participants were instructed to list members of the indicated category (causes of death or modes of transportation). ${ }^{5}$ Participants were given unlimited time to complete this task. The experimenter noted the time that participants began the task. In addition, the instructions following the task requested that participants record the time of completion (in hours, minutes, and seconds) according to the clock in the room. Thus, we

\footnotetext{
${ }^{4}$ In fact, Wegener and his colleagues have evidence that the enhanced mood management concerns of happy individuals can lead them to engage in mood-threatening activities when they believe it will help them avoid negative events in the future. Specifically, Chen et al. (2005) found in a persuasion context that happy people would increase processing of negative material when it can enhance long-term mood management. Thus, there is an empirical precedent within hedonic contingency theory work to expect that happy people might engage in a potentially mood-threatening task in order to satisfy overarching mood management goals. What our transformation hypothesis espouses is that, consistent with Wegener and Petty's (2001) contention, happy people might actively and creatively alter their performance of the task (à la Sansone et al., 1992) in order to make it more enjoyable and thereby satisfy their mood management goals.

${ }^{5}$ As in Hirt et al. (1997), participants were also given explicit stop rule instructions (cf. Martin et al., 1993). Participants in the enjoy-stop rule condition were told that "we would like you to stop listing items when you no longer enjoy the task." Those in the time-to-stop condition were told that "we would like you to stop listing items when you feel it is time to stop." Because this variable is not directly relevant to the present discussion, we do not discuss it any further. However, readers should be reassured to find that we did indeed replicate the findings obtained in Hirt et al. (1997) with regard to this variable (i.e., Mood $\times$ Stop Rule interactions on quantitative measures of performance, such as number generated and time spent on task, as well as on our measure of posttask interest, but no Mood $\times$ Stop Rule interaction on our measure of creativity). More important, task did not interact with stop rule for any of our dependent measures. Readers interested in more details are encouraged to contact Edward R. Hirt for additional information.
} 
were able to record unobtrusively the amount of time each participant spent on the task.

After completing the creativity task, participants completed a second mood manipulation check, identical to the first. Participants then completed a posttask interest measure, parallel to the pretask measure except that the statements were now phrased in the past tense (e.g., "Thinking about different causes of death/ modes of transportation was interesting"). After completing these items, participants were thanked and debriefed.

\section{Results}

Mood manipulation check. Responses on the mood manipulation checks were subjected to factor analysis. This analysis revealed two factors that accounted for $69.5 \%$ of the variance. Two factor scores were computed for each mood assessment: (a) a positive affect index (six items: happy, satisfied, pleased, delighted, content, glad; $\alpha=.91$ ) and (b) a negative affect index (six items: annoyed, depressed, miserable, gloomy, sad, frustrated; $\alpha=$ $.90)$, and ANOVAs were performed on these factor scores. For the first mood assessment (immediately after the video clips), we obtained large main effects of mood on both the positive, $F(2$, $202)=110.6, p<.001$, and the negative affect indices, $F(2$, $202)=55.3, p<.001$. As expected, participants in the happy mood condition expressed greater positive affect $(M=21.2)$ than did participants in both neutral $(M=15.7)$ and sad mood conditions $(M=10.6$; both $t \mathrm{~s}>3.0, \mathrm{ps}<.01)$. Conversely, those in the sad mood condition expressed more negative affect $(M=12.3)$ than those in either the neutral $(M=9.5)$ or happy mood conditions $(M=9.0$; both $t \mathrm{~s}>2.2, p \mathrm{~s}<.05)$. No other significant effects were obtained. Thus, our mood manipulation appears to have been very successful.

Pretask interest. In our earlier work (Hirt et al., 1997, 1996), we found that pretask interest was enhanced by happy mood. However, we were particularly interested in whether the hedonic features of the category would affect perceptions of pretask interest. An ANOVA on this measure revealed no main effect of mood $(F<1, n s)$. Instead, a main effect of task was observed, $F(1$, $204)=14.54, p<.001$, with participants reporting greater task interest in generating modes of transportation $(M=20.1)$ than in causes of death $(M=17.3)$. This main effect was qualified by a Mood $\times$ Task interaction, $F(2,204)=13.18, p<.001$. These data are presented in the second column of Table 2. Simple effects analyses revealed that happy mood indeed led to significantly

Table 2

Study 2: Mean Pretask and Posttask Interest as a Function of Mood and Task

\begin{tabular}{lccccc}
\hline & \multicolumn{2}{c}{ Pretask Interest } & & \multicolumn{2}{c}{ Posttask Interest } \\
\cline { 2 - 3 } \cline { 5 - 6 } Mood & Transportation & Death & & Transportation & Death \\
\hline Happy & $23.1_{\mathrm{a}}$ & $15.2_{\mathrm{c}}$ & & $21.2_{\mathrm{a}}$ & $21.4_{\mathrm{a}}$ \\
Neutral & $18.5_{\mathrm{b}}$ & $18.7_{\mathrm{b}}$ & & $18.6_{\mathrm{b}}$ & $17.9_{\mathrm{b}}$ \\
Sad & $18.8_{\mathrm{b}}$ & $18.1_{\mathrm{b}}$ & & $18.9_{\mathrm{b}}$ & $17.4_{\mathrm{b}}$ \\
\hline
\end{tabular}

Note. The Pre- and Posttask Interest scale scores range from 5 to 35, with higher numbers indicating greater task interest. Means not sharing a common subscript differ significantly at $p<.05$. greater pretask interest than either neutral or sad mood (both $t \mathrm{~s}>$ 3.3 , $p$ s $<.001)$ when the task involved generating modes of transportation, $F(2,99)=8.27, p<.001$, replicating our earlier work (Hirt et al., 1997). However, when anticipating the task of generating causes of death, happy mood resulted in significantly less pretask interest than either neutral or sad mood (both $t \mathrm{~s}>2.4$, $p$ s $<.01), F(2,105)=5.05, p<.01$. It is interesting that there were no differences between the neutral and sad mood conditions, suggesting that those in the happy mood condition were particularly attuned to the potential hedonic consequences of these different tasks, in line with the predictions of hedonic contingency theory.

Creativity of responses. Our primary interest was in the positive mood-cognitive flexibility link. More important, Hirt et al. (1997) found that on their creativity measure, only a mood main effect was obtained, such that happy participants exhibited greater cognitive flexibility than those in the other mood conditions. In Study 2, we were particularly interested in seeing whether these mood effects on cognitive flexibility would be moderated by the hedonic qualities of the task.

As in Hirt et al. (1997), creativity was measured by having independent raters code generated responses on dimensions of fluency, flexibility, and originality. Fluency was assessed simply by counting up the number of responses each participant generated. Flexibility was then assessed by each rater on the basis of the number of distinct or different categories of responses represented in a given participants' protocol (interrater reliabilities for this index ranged from .81 to .95). Originality was assessed on the basis of frequency counts. All listed responses were catalogued, and the uniqueness and relevance of each response was noted (interrater reliabilities ranged from .85 to .96 ). Responses that were not rated as relevant or valid for the denoted category were discarded and were not included in the fluency, flexibility, or originality measures. For data analytic purposes, we then assigned an originality score to each valid individual response along a 5-point scale, with 1 indicating the most common set of responses and 5 indicating the most novel and original responses (reliabilities ranged from .87 to .98 ). Examples of the kinds of items in each category for the modes of transportation task are as follows: (a) car, boat; (b) skateboard, camel; (c) parachute, bobsled; (d) pogo stick, e-mail; (e) lysergic acid diethylamide (LCD), imagination. Examples of the kinds of items in each category for the causes of death task are as follows: (a) heart attack, car accident; (b) shark attack, dehydration; (c) electrocution, euthanasia; (d) ritual sacrifice, spontaneous combustion; (e) being thought out of existence, experimenter got hungry and eats you. Once these originality ratings were determined, we summed them into a total creativity score. However, this total creativity score was highly correlated with fluency/number generated, $r(207)=.94, p<.001$. To obtain an index of creativity independent of the number generated, we divided the total creativity score by the number generated to compute the average creativity of participants' responses.

Fluency. An ANOVA on the number of items generated revealed only a marginal effect of mood, $F(2,204)=2.46, p<.09$. Happy participants generated overall more responses $(M=18.03)$ than did neutral $(M=15.58)$ or sad participants $(M=15.23$; both $t \mathrm{~s}>2.0, p \mathrm{~s}<.05)$.

Flexibility. We used an ANOVA on the number of distinct types of responses and obtained a significant mood main effect, 
$F(2,204)=22.25, p<.001$. Participants in the happy mood condition generated a broader range of different responses $(M=$ 4.74) than did either neutral $(M=3.83)$ or sad mood participants $(M=3.85)$. There was no task main effect or Mood $\times$ Task interaction (both $F \mathrm{~s}<1, n s$ ). Indeed, for both tasks individually, the mood main effect was significant (both $F \mathrm{~s}>7.5$, $p \mathrm{~s}<.01$ ). Thus, it appears that happy mood led to greater flexibility in responding.

Originality. An ANOVA on our average creativity measure also revealed a main effect of $\operatorname{mood}, F(2,202)=23.50, p<.001$. Participants in the happy mood condition $(M=1.79)$ generated more original responses than participants in both the neutral $(M=$ $1.52)$ and sad mood conditions $(M=1.37$; both $t \mathrm{~s}>3.2, p \mathrm{~s}<$ $.001)$. There was also a main effect of task, $F(1,202)=12.81, p<$ .001 , such that those who generated modes of transportation were more creative than those who generated causes of death. However, these main effects were qualified by a marginal Mood $\times$ Task interaction, $F(2,202)=2.90, p=.057$. Table 3 presents these data. Simple effects tests revealed that although the mood effects were observed for both tasks, the magnitude of the differences were much greater for the modes of transportation task, $F(2,99)=$ $26.44, p<.001$, than the causes of death task, $F(2,103)=4.24$, $p=.017$. Nevertheless, in all cases, happy participants were more creative than both neutral and sad participants, suggesting that the negative valence of the causes of death task did not eliminate the positive mood-cognitive flexibility link.

Consequences of cognitive flexibility. Given these differences in cognitive flexibility of performance as a function of mood, we next examined the consequences of being creative for subsequent mood and posttask interest. If our hedonic contingency account is correct, then being creative at the task should maintain or enhance the positive mood of happy individuals and sustain their interest in performing such a task.

Table 3

Study 2: Mean Creativity Scores as a Function of Mood and Task

\begin{tabular}{lrr}
\hline & \multicolumn{2}{c}{ Task } \\
\cline { 2 - 3 } Mood & Transportation & Death \\
\hline Happy & & \\
Fluency & 18.06 & 18.00 \\
Flexibility & 4.85 & 4.62 \\
Originality & 1.95 & 1.62 \\
Neutral & & \\
Fluency & 16.42 & 14.79 \\
Flexibility & 3.79 & 3.87 \\
Originality & 1.60 & \\
Sad & & 1.43 \\
Fluency & 15.83 & 3.83 \\
Flexibility & 3.86 & 1.36 \\
Originality & 1.39 & \\
\hline
\end{tabular}

Note. Fluency was measured in terms of number of generated responses. Flexibility reflects the number of different categories of responses included in a given participant's protocol. Originality reflects the average creativity score for each participant, determined by dividing the total creativity of responses by the number of responses generated. The correlations between these three dimensions of creativity were as follows: fluency/flexibility, $r(210)=.67, p<.001$; fluency/originality, $r(210)=.39, p<.001$; flexibility/originality, $r(210)=.38, p<.001$.
Posttask mood check. ANOVAs performed on the posttask mood manipulation check revealed significant main effects of mood condition on both the positive affect, $F(2,202)=8.45, p<$ .001 , and negative affect indices, $F(2,202)=8.76, p<.001$. Happy and neutral participants continued to have more positive affect than sad participants (both $t \mathrm{~s}>2.5, p \mathrm{~s}<.05$ ), and sad participants expressed more negative affect than both happy and neutral participants (both $t \mathrm{~s}>2.4, p \mathrm{~s}<.05$ ). In addition, there were also significant main effects of task type on both indices $(F \mathrm{~s}>10.0, p s<.001)$. Participants who listed causes of death reported less positive affect and more negative affect than those who listed modes of transportation. More important, there were also significant Mood $\times$ Task interactions on both the positive, $F(2,202)=2.98, p<.05$, and negative affect measures, $F(2$, $202)=4.41, p<.02$. Table 4 presents these data. Whereas both sad and neutral mood participants (all $t \mathrm{~s}>2.2, p \mathrm{~s}<.05$ ) had significantly less positive affect and greater negative affect after listing the mood-threatening task (causes of death) than the neutral or potentially mood-enhancing task (modes of transportation), happy participants did not (both $t \mathrm{~s}<1, n s$ ). Thus, it appears that the mood of happy individuals was not sabotaged by the causes of death task.

Posttask interest. An ANOVA conducted on posttask interest ratings found a significant main effect of mood condition, $F(2$, $204)=6.84, p<.001$. More important, there were no effects of task on this variable, suggesting that the valence of the task had no effect on participants' posttask interest (see the fourth column of Table 2). Separate analyses conducted for the modes of transportation, $F(2,99)=3.46, p<.05$, and causes of death tasks, $F(2$, $105)=5.00, p<.01$, revealed that happy participants expressed greater posttask interest than both neutral or sad participants for both tasks.

This finding is particularly noteworthy with regard to the causes of death task. Recall that happy participants expressed significantly less pretask interest in performing this task. However, on this posttask interest measure, these same participants now expressed significantly greater interest in the task. Indeed, it appears that the task interest of happy participants was enhanced following performance of this potentially mood-threatening task, $t(36)=$ 6.36, $p<.001$.

Mediational analyses. Given these effects, our final analyses examined whether the enhanced cognitive flexibility of happy participants' responses mediated the maintenance of positive mood and task interest. To do this, we conducted regression analyses following the procedures outlined by Baron and Kenny (1986). We computed two orthogonal contrasts from our three-level mood variable: a happy mood contrast (happy mood $=2$; neutral mood $=-1 ;$ sad mood $=-1$ ) and a sad/neutral contrast (happy $\operatorname{mood}=0 ;$ neutral $\operatorname{mood}=1 ; \operatorname{sad} \operatorname{mood}=-1$ ). Main effects of task as well as interaction terms between the two mood contrasts and task were computed, resulting in a total of five variables in the base model. Variables were mean centered, and regressions were then performed on the two key outcome measures (posttask mood and interest). Confirming the ANOVA results, these models were highly significant. In a final step, we then added the two mediators (number of different categories, average creativity) to the equation predicting each of the outcome measures. Average creativity significantly added to the prediction of posttask positive mood $(\beta=$ $.21), t(198)=2.91, p=.004$, and posttask interest $(\beta=.28)$, 
Table 4

Study 2: Mean Posttask Positive and Negative Affect Scores as a Function of Mood and Task

\begin{tabular}{lccccc}
\hline & \multicolumn{2}{c}{ Positive affect } & & \multicolumn{2}{c}{ Negative affect } \\
\cline { 2 - 3 } \cline { 5 - 6 } Mood & Transportation & Death & & Transportation & Death \\
\hline Happy & $17.1_{\mathrm{a}}$ & $15.9_{\mathrm{a}}$ & & $8.07_{\mathrm{a}}$ & $8.87 \mathrm{a}$ \\
Neutral & $15.8_{\mathrm{a}, \mathrm{b}}$ & $13.5_{\mathrm{b}}$ & & $7.72_{\mathrm{a}}$ & $10.5_{\mathrm{a}}$ \\
Sad & $14.2_{\mathrm{b}}$ & $11.2_{\mathrm{c}}$ & & $9.75_{\mathrm{b}}$ & $13.3_{\mathrm{b}}$ \\
\hline
\end{tabular}

Note. In each column, means not sharing a common subscript differ significantly at $p<.05$.

$t(200)=3.82, p<.001$. Moreover, Sobel tests revealed that the addition of average creativity substantially reduced the betas for the main effect of the happy-mood contrast for posttask positive mood (beta dropped from .185 to $.051, z=2.64, p<.01$ ) and posttask interest (beta dropped from .248 to $.071, z=3.27, p=$ $.001)$. The number of different categories did not significantly add to the prediction over the effects of average creativity.

\section{Discussion}

The results of Study 2 illustrated the generality of the observed positive mood-cognitive flexibility link. Despite the fact that happy individuals expressed significantly less pretask interest when the task involved the mood-threatening topic (causes of death) than the neutral topic (modes of transportation), they still generated significantly more creative responses to the task than participants in other mood states. Furthermore, their enhanced creativity served to sustain their positive mood and interest in performing the task.

We entertained two potential hypotheses concerning the effects of providing participants with a negatively valenced task. The selectivity hypothesis argued that happy individuals would withdraw effort from the task when it involved a potentially moodthreatening topic, generating less (and less creative) exemplars. Clearly, this was not the case in Study 2. Alternatively, the transformation hypothesis argued that happy individuals would make efforts to transform the task into something pleasant, thereby sustaining their positive mood. This hypothesis predicted that happy participants would show greater creativity for both tasks as a means of sustaining or enhancing their positive mood. Indeed, the results of Study 2 strongly support the transformation hypothesis. Consistent with Wegener and Petty's (2001) contention, the data from the posttask mood and interest measures indicate that being creative did successfully serve the mood management goals of happy individuals. These observations led us to pursue in more depth exactly what happy individuals might have done to insulate themselves from the potentially mood-threatening consequences of the causes of death task.

An examination of the nature of the responses generated for the causes of death task by individuals in the different mood conditions proved to be particularly revealing. We noticed that whereas most individuals generated lists of responses that were very matter-of-fact and straightforward, as if listed right out of a medical book (homicide, suicide, stroke, cancer, accident, drug overdose, etc.), others provided lists that included many sensational, graphic, and cartoon or "horror movie" types of causes (e.g., spontaneous combustion, experimenter gets hungry and eats you, small parasite burrows into esophagus, burned at the stake, piano falls 10 stories onto your head, sticking a bomb in someone's pants). We examined specifically the number of responses participants in the causes of death condition generated for each of these two categories: sensationalistic/comical and actuarial/medical. These analyses revealed a main effect of mood for the sensationalistic/comical category, $F(2,77)=6.49, p=.002$, such that happy participants generated significantly more exemplars in this category $(M=4.35)$ than did either neutral $(M=1.17)$ or sad $(M=1.11)$ participants (both $t \mathrm{~s}>2.5, \mathrm{ps}<.05) .{ }^{6}$ Conversely, a main effect of mood was obtained for the actuarial/medical category, $F(2,77)=3.98, p=.023$, with both neutral $(M=5.48)$ and sad participants $(M=5.39)$ generating significantly more medical exemplars than happy individuals $(M=3.39$; both $t \mathrm{~s}>2.3$, $p \mathrm{~s}<$ $.05)$. Thus, it appears that happy individuals were able to successfully transform the causes of death generation task into one that was no longer mood threatening.

The results of Study 2 attest to the ability of happy individuals to manipulate the given task in a manner that defused its potentially mood-threatening consequences. Happy participants did not simply withdraw or disengage from the task because the domain presented a threat to their positive mood, as would be predicted by the selectivity hypothesis. Instead, consistent with the transformation hypothesis, they were able to find a way to flexibly transform the task into something fun and entertaining, enabling them to sustain their happy mood and task interest despite the negative valence of the domain (causes of death).

Although the results of Study 2 are consistent with a hedonic contingency interpretation, we must acknowledge that several other mood theories could also account for the observed effects. Recall that positive mood has also been shown to affect the strategies with which people approach various tasks. Schwarz's (1990) cognitive tuning view argues that positive moods signal that the current situation is safe and allow the individual to playfully explore his or her environment, attempt novel approaches and strategies, and take risks. It may not only be the case that happy participants construe the task from multiple perspectives but also that their happy mood empowers them to take the risk of providing more novel responses to the task. That is, we cannot distinguish from our data whether happy participants were the only ones who thought about these more sensationalistic or graphic responses or were just the only ones willing to report them. Furthermore, Trope and his colleagues (Trope, Ferguson, \& Raghunatan, 2001; Trope, Gervey, \& Bolger, 2003; Trope \& Neter, 1994) have promoted the view that positive mood serves as a resource, such that individuals in happy mood are able to forgo short-term affective

\footnotetext{
${ }^{6}$ These sensationalistic/comical responses were not just concentrated in the protocols of a few individuals. An examination of the frequency of participants who generated responses in this category revealed a significan mood effect, $\chi^{2}(2, N=80)=6.84, p<$. 05. Happy participants were more likely to generate responses in this category $(65.5 \%)$ than either neutral $(41.4 \%)$ or sad participants $(32.1 \%)$. In addition, these responses did not appear to be the result of increased task persistence, for they were as likely to occur in the first half as in the second half of a given participant's protocol. Finally, it is important to note that none of the sensationalistic/ comical responses were suggested by the film clips used in the positivemood induction.
} 
goals in the service of longer term (and higher level of construal) learning goals. Their research has shown that happy individuals are more willing to view feedback focusing on their weaknesses and deficiencies when it has diagnostic value for future goals. Thus, the effects observed in Study 2 could also reflect differences in cognitive strategy, risk taking, or differences in goal pursuit. Although none of these other views would necessarily predict that being creative would serve to sustain or enhance posttask mood or interest per se, it is possible that achieving mood management goals was not the driving motivation underlying the enhanced cognitive flexibility of happy participants (and was instead a desirable, yet unintended consequence accrued from an entirely different process). Thus, in order to argue convincingly in favor of our hedonic contingency account, we needed to demonstrate that happy people strategically use cognitive flexibility for the motive of sustaining or enhancing their positive mood. For these reasons, we conducted Study 3.

\section{Study 3}

Study 3 was designed to provide direct evidence that happy participants are creative in the service of mood management concerns, consistent with a hedonic contingency view. In Study 3, we asked whether happy participants would continue to demonstrate greater cognitive flexibility when they did not believe that being creative would sustain or enhance their current positive feelings. In Study 3, as in Studies 1 and 2, participants were either induced into happy, sad, or neutral moods using video clips. Additionally, participants in each mood condition were placed into either the mood-freezing or nonmood-freezing condition. Manipulations inducing mood-freezing conditions have been used successfully in past research (Manucia, Baumann, \& Cialdini, 1984; Tice, Bratslavsky, \& Baumeister, 2001) to eliminate the mood management motive for engaging in a particular activity. Participants then completed a cognitive flexibility task.

We predicted that participants in the nonmood-freezing condition would replicate past research, such that those in a happy mood should perform significantly more creatively than those in the neutral and sad mood conditions. For those in the mood-freezing condition, the predictions were different. We hypothesized that those in the happy mood-freezing condition would show no difference in the creativity of their performance relative to those in neutral or sad moods. This prediction provides a direct test of the role that hedonic contingency concerns play in the positive mood-cognitive flexibility link: If participants are led to believe that their mood cannot be altered, according to hedonic contingency theory, then they should no longer be motivated to be creative if doing so cannot maintain or improve their mood. We already know, based on the results of Hirt et al. (1997), that a mood-as-input/mood-as-information account for the observed positive mood-cognitive flexibility link is untenable. Using this same paradigm, recall that Hirt et al. (1997) demonstrated that happy participants provided with a mood source cue (rendering their mood nondiagnostic) continued to show enhanced cognitive flexibility. However, the mood-congruent retrieval hypothesis would make different predictions for Study 3 in that it does not posit mood management concerns as the primary motivation for the positive moodcognitive flexibility link. Thus, the mood-congruent retrieval view would predict that those in a happy mood should continue to respond more creatively regardless of mood-freezing condition. In this way,
Study 3 allows us to distinguish hedonic contingency concerns from other possible mechanisms.

\section{Method}

Participants. Participants were 157 introductory psychology students (65 men, 92 women) at Indiana University Bloomington. They participated in partial fulfillment of a course requirement. Participants were tested in groups of 3 but were placed in individual cubicles.

Procedure. When participants entered the lab, they were greeted by a male experimenter who ushered them into an individual cubicle. After participants completed the informed consent statement, the experimenter began the video clips. This mood manipulation was the same one we used in Studies 1 and 2 and in Hirt et al. (1997). After watching all three of the clips, participants completed a mood measure manipulation check, which asked them to assess on a scale from 1 (not at all) to 7 (very much) to what degree a particular adjective fit their current mood. The adjectives included the words annoyed, happy, depressed, miserable, satisfied, gloomy, pleased, sad, delighted, content, frustrated, and glad.

After completing the mood measure, a female experimenter entered each individual cubicle with a lit aromatherapy candle and stated that the second experiment examined the effects of aromatherapy on perceptual and cognitive tasks. The experimenter asked the participant to smell the candle and placed the candle on the desk in the cubicle. Additionally, the experimenter informed the participant that similar research had been done at the University of Michigan and that we were replicating some of that research. In the nonmood-freezing condition, the experimenter asked the participant if he or she had any questions and exited the cubicle. In the mood-freezing condition, the experimenter explained that one of the side effects of this particular aromatherapy candle is a moodfreezing effect such that your mood would not change for a fixed period of time. The experimenter asked whether the participant had questions and exited the cubicle. This mood-freezing procedure was adapted from Tice et al. (2001).

At this point, the participants completed a cognitive flexibility measure in which they were asked to list modes of transportation (Hirt et al., 1997). Participants could list as few or as many as they desired. No instructions were given regarding an appropriate number of responses or an amount of time that should be spent on the task. Instead, the instructions informed the participants that they should type done when they finished listing modes of transportation. After completing the cognitive flexibility task, participants completed a posttask interest measure and a posttask mood manipulation check. This marked the end of the experiment, at which point participants were thanked, debriefed, and probed for suspicion regarding the aromatherapy candle.

\section{Results}

Mood manipulation check. Responses on the mood measure indicated that our mood manipulation was successful. A significant main effect on our positive affect index $(\alpha=.92)$ revealed that happy participants $(M=20.22)$ reported more positive affect than either neutral $(M=14.71)$ and sad participants $(M=12.37), F(2$, $151)=32.34, p<.001$. A similar main effect was observed on our negative affect index $(\alpha=.87), F(2,151)=22.18, p<.001$, with 
sad participants $(M=12.82)$ reporting greater negative affect than either neutral $(M=10.07)$ or happy participants $(M=7.33)$.

Mood-freezing manipulation check. Participants' recall of the mood-freezing instructions given was perfect. However, in order to test whether participants believed that the candle had mood-freezing effects, we examined participants' responses to the mood measure responses given at the end of the study. In particular, we were interested in whether the instruction manipulation would lead participants in the valenced mood conditions to report stronger posttask moods. On the posttask positive mood index, we obtained only a mood main effect, $F(2,151)=9.89, p<.001$. Happy participants continued to report more positive affect $(M=18.30)$ than participants in the neutral $(M=14.28)$ or sad mood conditions $(M=14.67$; both $t \mathrm{~s}>2.5, p \mathrm{~s}<.01)$. On this index, there was no Mood $\times$ Instruction interaction; however, this is not particularly surprising, given the generally favorable response to this cognitive flexibility task. However, on the posttask negative affect index, we obtained both a main effect of mood, $F(2,151)=8.05, p<.001$, and a Mood $\times$ Instruction interaction, $F(2,151)=3.68, p=.027$. In the mood-freezing condition, sad participants reported significantly more negative affect $(M=11.13)$ than either neutral $(M=8.68)$ or happy participants $(M=6.89$; both $t \mathrm{~s}>2.4, p \mathrm{~s}<.01)$. In the nonmood-freezing conditions, there were no differences across the three mood conditions $(F<1, n s)$. These data suggest that participants were indeed influenced by the experimental instructions regarding the mood-freezing effects of the candle. ${ }^{7}$

Creativity of responses. Of greatest interest in the present study was the creativity of participants' responses. As in Study 2, we had independent raters code responses for fluency, flexibility, and originality. Interrater agreement on all of these ratings ranged from .83 to 1.00 . Table 5 presents these data.

Fluency. There was a significant Mood $\times$ Instruction interaction observed on the number of responses generated, $F(2,151)=$

Table 5

Study 3: Mean Creativity Scores as a Function of Mood and Instruction Condition

\begin{tabular}{lcc}
\hline & \multicolumn{2}{c}{ Instruction condition } \\
\cline { 2 - 3 } Mood & Nonmood freezing & Mood freezing \\
\hline Happy & & \\
$\quad$ Fluency & 14.18 & 9.48 \\
Flexibility & 4.29 & 3.44 \\
$\quad$ Originality & 1.69 & 1.38 \\
Neutral & & \\
Fluency & 10.63 & 10.83 \\
Flexibility & 3.41 & 3.65 \\
Originality & 1.32 & 1.34 \\
Sad & & \\
Fluency & 11.46 & 12.17 \\
Flexibility & 3.64 & 3.63 \\
Originality & 1.36 & 1.34 \\
\hline
\end{tabular}

Note. Fluency was measured in terms of number of generated responses. Flexibility reflects the number of different categories of responses included in a given participant's protocol. Originality reflects the average creativity score for each participant, determined by dividing the total creativity of responses by the number of responses generated. The correlations between these three dimensions of creativity were as follows: fluency/flexibility, $r(157)=.70, p<.001$; fluency/originality, $r(157)=.36, p<.001 ;$ flexibility/originality, $r(157)=.48, p<.001$.
$3.59, p=.03$. Consistent with past research, mood significantly affected the number of responses generated in the nonmoodfreezing conditions. Happy participants generated a greater number of responses $(M=14.2)$ than either neutral $(M=10.6)$ or sad participants $(M=11.5$; both $t \mathrm{~s}>2.0, p \mathrm{~s}<.05)$. However, no mood effects were observed in the mood-freezing conditions. No other effects were obtained on this measure.

Flexibility. An examination of the number of different categories revealed both a mood main effect, $F(2,151)=3.17, p=$ .045 , and a Mood $\times$ Instruction interaction, $F(2,151)=8.67, p<$ .001 . In the nonmood-freezing conditions, happy participants generated more different categories of responses $(M=4.29)$ than neutral $(M=3.41)$ or sad participants $(M=3.64$; both $t \mathrm{~s}>2.5$, $p s<.001)$. As was the case with the fluency measure, these mood effects disappeared in the mood-freezing conditions.

Originality. Analysis of our average creativity measure also revealed a main effect of mood, $F(2,151)=5.10, p<.01$, and a Mood $\times$ Instruction interaction, $F(2,151)=3.11, p<.05$. Subsequent analyses of this interaction revealed a significant effect of mood in the nonmood-freezing condition, $F(2,80)=9.74, p<$ .001 . The responses of participants in the happy nonmood-freezing condition $(M=1.69)$ showed significantly greater originality than participants in the neutral $(M=1.32)$ and sad nonmood-freezing conditions $(M=1.36$; both $t \mathrm{~s}>3.2, p \mathrm{~s}<.001)$. Again, in the mood-freezing conditions, there were no differences as a function of mood, $F(2,71)=0.11, n s$.

Looking at these results another way, we found that only the originality of happy participants significantly differed as a function of mood-freezing condition. That is, participants in the happy mood-freezing condition gave significantly less creative responses on average than those in the happy nonmood-freezing condition $(M \mathrm{~s}=1.69$ vs. 1.38$), t(53)=-2.20, p=.032$.

Posttask interest. In addition, a significant Mood $\times$ Instruction interaction was observed on the measure of posttask interest, $F(2,151)=4.45, p=.013$. Significant effects of mood were obtained in the nonmood-freezing conditions, paralleling past research. Happy participants expressed greater task interest $(M=$ 5.11) than either neutral $(M=4.52)$ or sad participants $(M=4.36$; both $t \mathrm{~s}>2.2, p \mathrm{~s}<.05)$. However, no mood effects were observed in the mood-freezing conditions. Collectively, these findings lend further support to a hedonic contingency explanation, in that when mood maintenance motives are eliminated (or at least lessened), the typical mood effects that are observed on these cognitive flexibility tasks disappear.

Given these results, as in Study 2, we examined whether the cognitive flexibility of participants' responses mediated these differences in posttask interest and posttask affect by conducting regression analyses. Because we found no significant effects on the hypothesized mediators (number generated, number of different categories, average creativity) or on one of the outcome variables (posttask interest) for the mood-freezing conditions, these analyses were performed only on the nonmood-freezing conditions. These

\footnotetext{
${ }^{7}$ Responses to the post hoc questions regarding suspicions also reveal that 1 participant was skeptical regarding the mood-freezing effects of the candle. This participant was a part-time employee of Bath \& Body Works, which is where the candles were purchased. Inclusion of this participant did not influence the results.
} 
analyses revealed that the addition of our average creativity measure $(\beta=.31), t(79)=2.08, p<.05$, for posttask positive affect; $(\beta=$ $.34), t(79)=2.62, p<.01$, for posttask interest, significantly reduced the happy-mood contrast in both cases (beta dropped from .27 to .11 for posttask positive affect; beta dropped from .24 to .05 for posttask interest), based on Sobel tests (both $z \mathrm{~s}>2.2, p \mathrm{~s}<.05$ ).

\section{General Discussion}

The primary goal of this series of studies was to examine the role of hedonic contingency theory in the positive mood-cognitive flexibility link. Previous research has established a robust correlation between positive mood state and creativity tasks assessing cognitive flexibility (cf. DeDreu et al., 2007). Although several possible mechanisms have been suggested as possible explanations for this relation, to date, no research has firmly established the role of any of these mechanisms. Indeed, our own previous research (Hirt et al., 1997) ruled out a mood-as-input account and argued that hedonic contingency theory might provide a viable account for the positive mood-cognitive flexibility link. Specifically, based on hedonic contingency theory, we predicted that individuals in happy moods might be more creative in the service of mood management motives, namely, to maintain or enhance their current (positive) affective state. Because hedonic contingency theory (Wegener \& Petty, 1994) posits that individuals in a positive mood have a narrower range of options that can satisfy their mood management concerns, this theory predicts that happy individuals must more carefully scrutinize the hedonic consequences of potential tasks and be more selective in their choices. Given the fact that being creative makes one feel good and enhances subsequent task interest, it stands to reason that happy individuals may choose to be more creative in order to sustain their positive mood. Individuals in other mood states, with a broader range of tasks to choose from that can satisfy their mood management concerns, should be less likely to evidence creative responding than happy individuals.

Indeed, our research provided strong support for the hypothesized role of hedonic contingency. Study 1 illustrated that relative to participants in neutral or sad moods, happy individuals selected tasks to a significantly greater extent on the basis of their hedonic consequences and less on the basis of personal interest or perceived difficulty. Moreover, when allowed the opportunity to choose among potential options, happy individuals showed a profound aversion to negatively valenced tasks, further attesting to their greater scrutiny of the hedonic consequences of potential options. An intriguing Study 1 finding of particular interest was the fact that happy individuals were also significantly more likely to weight potential for creativity in their task choice. It thus appears that happy individuals look for tasks that afford them the opportunity to be creative, presumably in order to provide them with an opportunity to achieve their mood management goals.

Study 2 shifted from examining task choice and manipulated the effects of the valence of the task participants were assigned to perform. Specifically, we wanted to assess whether in the service of mood management concerns, happy participants would withdraw effort and illustrate less creativity when confronted with a potentially mood-threatening task (the selectivity hypothesis) or actively attempt to transform the task into something more pleasant by being creative (the transformation hypothesis). Results indicated that happy participants were more creative than partici- pants in other mood states, even when confronted with a negatively valenced and potentially mood-threatening task (causes of death). Indeed, content analyses indicated that happy participants did indeed flexibly transform the task into something more fun and interesting. As a result, happy participants were able to maintain their positive mood state and expressed greater posttask interest, despite the negative valence of the domain. Indeed, Study 2 provided evidence that being creative proved successful in achieving desirable mood management goals.

The most direct evidence for the role of hedonic contingency in the positive mood-cognitive flexibility link comes from Study 3. If indeed it is the case that happy participants are more creative as a way to maintain or enhance their positive mood, then happy participants who are led to believe that their moods are "frozen" and are not susceptible to change should no longer demonstrate greater creativity. That is, under conditions in which being creative cannot sustain or improve mood, the link between positive mood and cognitive flexibility would be severed, and we would anticipate no differences in creativity across mood conditions. The results of Study 3 provided strong support for our predictions. Happy participants in the nonmood-freezing condition (who believed that their moods were susceptible to change) were indeed the most creative. However, happy participants in the mood-freezing condition (who believed that their current happy mood was frozen, thus eliminating the need to engage in mood management efforts) showed no greater creativity than participants in the other mood conditions (and significantly less creativity than happy participants in the nonmood-freezing condition). This finding powerfully demonstrates that when led to believe that their moods were not malleable, happy participants were no longer motivated to be creative.

\section{The Transformation Hypothesis}

Perhaps the most intriguing finding in this set of studies was the fact that happy participants in Study 2 continued to show enhanced creativity even when given the mood-threatening task of generating causes of death. Indeed, it is clear from the results of Study 1 that when given the choice, happy participants actively avoid such tasks that threaten to sabotage their positive feelings. However, it is important to recall that Study 2 participants were assigned the mood-threatening task; indeed, they did not choose to engage in this task on their own accord. When confronted with this moodthreatening task, happy individuals successfully transformed the task into something that was no longer mood threatening: They generated causes of death that were more sensationalistic, graphic, and humorous, often mirroring things that they had read about or seen in stories, comic books, and horror movies, a tendency that was not observed among neutral or sad participants. As a result, the task (which according to pretask interest measures was aversive to happy participants) did not sabotage their mood and led to greater posttask interest.

At first blush, many readers may believe that our transformation hypothesis is inconsistent with the tenets of hedonic contingency theory. After all, according to this theory, happy people scrutinize tasks more carefully than individuals in other moods in order to protect their positive mood state. However, an important aspect of hedonic contingency theory is the flexibility with which individuals can achieve their overarching mood management goals. Specifically with regard to the positive mood-creativity relationship, 
Wegener and Petty (2001) argued that happy participants "might be more likely to engage in the task in a manner that makes the task more enjoyable" (p. 197). Indeed, this is precisely what we found. Moreover, our findings are entirely consistent with a great deal of past research illustrating that happy people are more flexible information processors (Isen \& Daubman, 1984; Isen et al., 1985) and have a greater ability to see both similarities and differences among a set of stimuli (Murray et al., 1990). We know from the work of Sansone et al. (1992) that individuals motivated to make the best of a dull or boring task can engage in interestenhancing strategies to transform the activity into something more interesting and positive to perform. In their research, individuals confronted with a boring copying task but convinced that there were health benefits accrued from doing it were able to change the task into something more pleasant (e.g., by using different styles of lettering). Thus, their research demonstrates that when motivated to do so, people demonstrate the ability to strategically transform a task into something less boring and tedious.

Consistent with Wegener and Petty's (2001) contention, our research suggests that individuals in a happy mood are more likely to show this self-regulatory ability. In Study 2, happy participants alone demonstrated the tendency to do this and, as a result, were able to sustain their mood and task interest. Thus, our findings fit well with the tenets of hedonic contingency theory and compellingly illustrate that in the service of their mood management goals, happy people have a greater motivation to transform the task in this manner. Indeed, we believe that it is important to emphasize that hedonic contingency theory does not only predict disengagement from mood-threatening activities. In the attitudes domain, Chen, Jeong, Wegener, Petty, and Smith (2005) have demonstrated that happy people will process and think carefully about negative information if they believe it will help them avoid negative events in the future. Relatedly, the mood-asresource view (Trope et al., 2001, 2003) argues that individuals in happy moods might forgo short-term affective goals in the service of longer term (high-construal) learning goals. Along with these other lines of work, the present research highlights the myriad of ways and the flexibility with which happy individuals can pursue their mood management goals.

We readily acknowledge that other mood perspectives provide compelling alternative accounts for these results. For instance, mood-congruent retrieval might underlie happy participants' tendency to produce more cognitively flexible responses. In addition, happy mood has been shown to evoke a more playful, exploratory processing style that leads people to take more novel and risky approaches to and strategies for problems (Schwarz, 1990). However, the results of Study 3 clearly suggest that hedonic contingency concerns play a pivotal role over and above other potential mechanisms. None of these other mechanisms would predict an effect of the mood-freezing instructions on the positive moodcognitive flexibility link. After all, if mood activates different material in memory or a more playful and riskier strategy, then these differences should emerge regardless of whether your mood is currently labile or not. Yet, in Study 3, we found that differences in creativity across mood conditions disappeared in the moodfreezing condition. Thus, eliminating the hedonic contingency component to the positive mood-cognitive flexibility relationship in Study 3 completely eliminated the effect.

But are these effects unique to the particular creativity tasks that we used in these studies? Indeed, we readily acknowledge that the specific creativity tasks were chosen explicitly because we wanted to unconfound ability and motivation. That is, we strategically chose measures of cognitive flexibility that would avoid the possibility that some participants might lack the knowledge or ability to demonstrate creative performance. For these sorts of tasks, it appears as if the motivation to be creative may be sufficient to result in more creative responses. Clearly, the range of tasks for which motivation is sufficient to produce greater creativity as well as further elucidation of the mechanism(s) by which motivation leads to more creative responding are important avenues for future research we are interested in pursuing. Nonetheless, these effects are consistent with observations made in other domains for which hedonic contingency has been readily applied (helping and persuasion), in which positive mood has been shown to increase the motivation to help or to process messages that are likely to sustain or enhance one's current mood. Although increased motivation does not necessarily guarantee success, it is clear that, other things being equal, motivation resulting from mood management concerns can increase the likelihood of engaging in these sorts of desirable behaviors.

\section{Caveats and a Coda}

Another important limitation of the present work that we must readily acknowledge is the exclusive focus on generation tasks as our indices of creativity. Indeed, such tasks have been used quite often in the literature and are included in the most famous instruments assessing creativity, like the TCCT (Torrance \& Ball, 1984) as well as Guilford's (1967) and Wallach and Kogan's (1965) creativity tests. Moreover, these tasks provide several relevant indices of cognitive flexibility (e.g., fluency, flexibility, originality) on which we can observe the effects of variables like mood state on various facets of creative performance. However, as we noted in the introduction, DeDreu et al. (2007) have illustrated that moods can affect creative performance via two different mechanisms: cognitive flexibility and persistence/perseverance. These authors found that positive moods enhance creativity through increased cognitive flexibility, whereas negative moods enhance creativity through increased task persistence and perseverance. Our interest in the present work was to examine the role of hedonic contingency in explaining the positive mood-creativity link consistently obtained on creativity tasks involving cognitive flexibility. On these sorts of tasks, our findings clearly show that hedonic contingency theory and its focus on mood management concerns provide a viable account for the effects of happy mood on cognitive flexibility. Nonetheless, it is unlikely that our hedonic contingency account would generalize to other sorts of creativity tasks that involve persistence/perseverance. Most notably, on these tasks, negative moods enhance creativity relative to positive moods, predictions contrary to hedonic contingency theory. On such tasks, it may well be the case that mood-as-input/mood-asinformation effects would be observed, akin to the findings of Martin and Stoner (1996), who found that negative-mood participants were more likely to generate additional responses in a creativity task when instructed to ask themselves, "Is my initial response a good one?" It may well be that on such tasks, concerns with the adequacy of performance lead negative-mood individuals to persist longer, resulting in the production of more creative responses due to increased persistence and perseverance, whereas 
positive-mood individuals may terminate the task early, for they perceive their initial responses as satisfactory. We admit that these comments are quite speculative at this point and require empirical validation and support before we can posit them with confidence. Nonetheless, they suggest an intriguing avenue for future research that might help to integrate the disparate set of findings that have plagued the mood-creativity literature.

Furthermore, although the present research provides strong evidence regarding the role of hedonic contingency concerns in the positive mood-cognitive flexibility link, we are not willing to argue that hedonic contingency theory constitutes the sole explanation for this relationship. Indeed, it is likely that several different mechanisms contribute to its robustness. In Hirt et al. (1997), we discussed the potential contributions of mood-congruent retrieval to the enhanced creativity of happy participants. Indeed, many of the findings exhibiting the enhanced flexibility of happy participants have been attributed to differences in mood-congruent retrieval. Positive mood provides a broader and richer cognitive context, facilitating the generation of more novel and creative associations. Given that we have not directly examined the role of mood-congruent retrieval in the present research, we cannot make any definitive statement about its contributions to the positive mood-cognitive flexibility link. These same caveats must be made regarding the potential contributions of Schwarz's (1990) cognitive tuning or Trope et al.'s (2001) mood-as-resource perspectives to this relationship. Nonetheless, we believe that the present research is the first to provide direct evidence for a mechanism underlying the positive mood-cognitive flexibility relationship. Although many potential explanations have been offered in the past, our findings lend strong support for the hypothesized role of hedonic contingency theory in the positive mood-cognitive flexibility link. In the service of hedonic contingency concerns, happy individuals appear to choose to be creative only when doing so will serve to maintain or enhance their positive mood. Although other explanations may also likely contribute to this relationship, we hope that the present research will serve to stimulate future efforts to isolate the roles that other mechanisms play in this robust relationship. In doing so, we hope to gain additional insight into the source of this powerful contributor to our creativity so that we can more effectively and reliably "unlock the muse within."

\section{References}

Ashby, F. G., Isen, A. M., \& Turken, A. U. (1999). A neuropsychological theory of positive affect and its influence on cognition. Psychological Review, 106, 529-550.

Baron, R. M., \& Kenny, D. A. (1986). The moderator-mediator variable distinction in social psychological research: Conceptual, strategic, and statistical considerations. Journal of Personality and Social Psychology, $51,1173-1182$

Bless, H., Bohner, G., Schwarz, N., \& Strack, F. (1990). Mood and persuasion: A cognitive response analysis. Personality and Social Psychology Bulletin, 16, 331-345.

Bodenhausen, G. (1993). Emotions, arousal, and stereotypic judgments: A heuristic model of affect and stereotyping. In D. M. Mackie \& D. L. Hamilton (Eds.), Affect, cognition, and stereotyping: Interactive processes in group perception (pp. 13-37). San Diego, CA: Academic Press.

Bransford, J., \& Johnson, M. (1972). Contextual prerequisites for understanding: Some investigations of comprehension and recall. Journal of Verbal Learning \& Verbal Behavior, 11, 717-726.
Carson, S. H., Peterson, J. B., \& Higgins, D. M. (2003). Decreased latent inhibition is associated with increased creative achievement in highfunctioning individuals. Journal of Personality and Social Psychology, 85, 499-506.

Chen, Z., Jeong, H., Wegener, D. T., Petty, R. E., \& Smith, S. M. (2005, May). Mood as a conditional resource: Long-term mood management in processing of persuasive communications. Paper presented at the annual meeting of the Midwestern Psychological Association, Chicago, IL.

Cialdini, R. B., \& Kenrick, D. (1976). Altruism as hedonism: A social development perspective on the relationship of negative mood state and helping. Journal of Personality and Social Psychology, 34, 907-914.

Clore, G., Schwarz, N., \& Conway, M. (1994). Affective causes and consequences of social information processing. In R. S. Wyer \& T. K. Srull (Eds.), Handbook of social cognition (Vol. 1, pp. 323-417). Hillsdale, NJ: Erlbaum.

DeDreu, C. K. W., Baas, M., \& Nijstad, B. A. (2007). Hedonic tone and activation level in the mood-creativity link. Manuscript submitted for publication.

Eames, C., \& Eames, R. (Directors). (1977). Powers of Ten [Motion picture]. United States: International Business Machines.

Forest, D., Clark, M. S., Mills, J., \& Isen, A. M. (1979). Helping as a function of feeling state and nature of the helping behavior. Motivation and Emotion, 3, 161-169.

Gasper, K. (2003). When necessity is the mother of invention: Mood and problem solving. Journal of Experimental Social Psychology, 39, 248-262.

George, J. M., \& Zhou, J. (2002). Understanding when bad moods foster creativity and good ones don't: The role of context and clarity of feelings. Journal of Applied Psychology, 87, 687-697.

Guilford, J. P. (1967). The nature of human intelligence. New York: McGraw-Hill.

Harada, J. (1983). The effects of positive and negative experiences on helping behavior. Japanese Psychological Research, 25, 47-51.

Hirt, E. R., Levine, G., McDonald, H., Melton, R., \& Martin, L. L. (1997). The role of mood in quantitative and qualitative aspects of performance: Single or multiple mechanisms? Journal of Experimental Social Psychology, 33, 602-629.

Hirt, E. R., Melton, J., McDonald, H., \& Harackiewicz, J. (1996). Processing goals, task interest, and the mood-performance relationship: A mediational analysis. Journal of Personality and Social Psychology, 71, 245-261.

Isen, A., \& Daubman, K. (1984). The influence of affect on categorization. Journal of Personality and Social Psychology, 47, 1206-1217.

Isen, A., Daubman, K., \& Nowicki, G. (1987). Positive affect facilitates creative problem solving. Journal of Personality and Social Psychology, 52, 1122-1131.

Isen, A., Johnson, M., Mertz, E., \& Robinson, G. (1985). Positive affect and the uniqueness of word association. Journal of Personality and Social Psychology, 48, 1413-1426.

Isen, A., \& Levin, P. (1972). Effect of feeling good on helping: Cookies and kindness. Journal of Personality and Social Psychology, 21, 384-388.

Isen, A., \& Means, B. (1983). The influence of positive affect on decisionmaking strategy. Social Cognition, 2, 18-31.

Isen, A., \& Shalker, T. (1982). The effect of feeling state on evaluation of positive, neutral, and negative stimuli: When you "accentuate the positive," do you "eliminate the negative"? Social Psychology Quarterly, 45, 58-63.

Isen, A., Shalker, T., Clark, M., \& Karp, L. (1978). Affect, accessibility of material in memory, and behavior: A cognitive loop? Journal of Personality and Social Psychology, 36, 1-12.

Isen, A., \& Simmonds, S. (1978). The effect of feeling good on a helping task that is incompatible with good mood. Social Psychology Quarterly, 41, 345-349.

Kahn, B., \& Isen, A. (1993). The influence of positive affect on variety seeking among safe, enjoyable products. Journal of Consumer Research, $20,257-270$. 
Kaufmann, G., \& Vosburg, S. K. (1997). "Paradoxical" mood effects on creative problem-solving. Cognition \& Emotion, 11, 151-170.

Kraiger, K., Billings, R., \& Isen, A. (1989). The influence of positive affective states on task perceptions and satisfaction. Organizational Behavior and Human Decision Processes, 44, 12-25.

Manucia, G., Baumann, D., \& Cialdini, R. (1984). Mood influences on helping: Direct effects or side effects? Journal of Personality and Social Psychology, 46, 357-364.

Martin, L., \& Stoner, P. (1996). Mood as input: What we think about how we feel determines how we think. In L. L. Martin \& A. Tesser (Eds.), Striving and feeling: Interactions among goals, affect, and selfregulation (pp. 279-301). Hillsdale, NJ: Erlbaum.

Martin, L., Ward, D., Achee, J., \& Wyer, R. (1993). Mood as input: People have to interpret the motivational implications of their moods. Journal of Personality and Social Psychology, 64, 317-326.

Murray, N., Sujan, H., Hirt, E. R., \& Sujan, M. (1990). The influence of mood on categorization: A cognitive flexibility interpretation. Journal of Personality and Social Psychology, 59, 411-425.

Nisbett, R., \& Wilson, T. (1977). Telling more than we can know: Verbal reports on mental processes. Psychological Review, 84, 231-259.

Parrott, W., \& Sabini, J. (1990). Mood and memory under natural conditions: Evidence for mood-incongruent recall. Journal of Personality and Social Psychology, 59, 321-336.

Petty, R. E., Gleicher, F., \& Baker, S. (1991). Multiple roles for affect in persuasion. In J. Forgas (Ed.), Emotion and social judgments (pp. 181-200). Oxford, England: Pergamon Press.

Plucker, J. A. (1999). Is the proof in the pudding? Reanalyses of Torrance's (1958 to present) longitudinal data. Creativity Research Journal, 12, $103-114$

Relyea, R. (Producer), \& Yates, P. (Director). (1968). Bullitt [Motion picture]. United States: Warner Brothers.

Rietzschel, E. F., Nijstad, B. A., \& Stroebe, W. (in press). Relative accessibility of domain knowledge and creativity: The effects of knowledge activation on the quantity and originality of generated ideas. Journal of Experimental Social Psychology.

Rushton, M. (Producer), \& Columbus, C. (Director). (1993). Mrs. Doubtfire [Motion picture]. United States: 20th Century Fox.

Sanna, L., Turley, K., \& Mark, M. (1996). Expected evaluation, goals, and performance: Mood as input. Personality and Social Psychology Bulletin, 22, 323-335.

Sansone, C., Weir, C., Harpster, L., \& Morgan, C. (1992). Once a boring task always a boring task? Interest as a self-regulatory mechanism. Journal of Personality and Social Psychology, 63, 379-390.

Schwary, R. L. (Producer), \& Redford, R. (Director). (1981). Ordinary People [Motion picture]. United States: Paramount Pictures.

Schwarz, N. (1990). Feelings as information: Informational and motivational functions of affective states. In R. Sorrentino \& E. T. Higgins (Eds.), Handbook of motivation and cognition: Foundations of social behavior (Vol. 2, pp. 527-561). New York: Guilford Press.

Schwarz, N. (1994). Judgment in a social context: Biases, shortcomings, and the logic of conversation. Advances in Experimental Social Psychology, 26, 123-162.

Schwarz, N., \& Bohner, G. (1996). Feelings and their motivational implications: Moods and the action sequence. In P. M. Gollwitzer \& J. A. Bargh (Eds.), The psychology of action: Linking cognition and motivation to behavior (pp. 119-145). New York: Guilford Press.

Schwarz, N., \& Clore, G. (1983). Mood, misattribution, and judgments of well-being: Informative and directive functions of affective states. Journal of Personality and Social Psychology, 45, 513-523.

Schwarz, N., \& Clore, G. L. (1988). How do I feel about it? The informative function of affective states. In K. Fiedler \& J. P. Forgas (Eds.), Affect, cognition, and social behavior (pp. 44-62). Toronto, Ontario, Canada: Hogrefe \& Huber.

Sinclair, R. (1988). Mood, categorization breadth, and performance ap- praisal: The effects of order of information acquisition and affective state on halo, accuracy, information retrieval, and evaluations. Organizational Behavior and Human Decision Processes, 42, 22-46.

Sinclair, R., \& Mark, M. (1995). The effects of mood state on judgmental accuracy: Processing strategy as a mechanism. Cognition \& Emotion, 9, 417-438.

Smith, S. M., \& Shaffer, D. (1991). The effects of good moods on systematic processing: Willing but not able or able but not willing? Motivation and Emotion, 15, 243-279.

Stanger, M. (Producer), \& Paluka, A. J. (Director). (1982). Sophie's Choice [Motion picture]. United States: Incorporated Television Company.

Teasdale, J., \& Fogarty, S. (1979). Differential effects of induced mood on retrieval of pleasant and unpleasant events from episodic memory. Journal of Abnormal Psychology, 88, 248-257.

Teasdale, J., \& Russell, M. (1983). Differential effects of induced mood on the recall of positive, negative and neutral words. British Journal of Clinical Psychology, 22, 163-171.

Tice, D., Bratslavsky, E., \& Baumeister, R. (2001). Emotional distress regulation takes precedence over impulse control: If you feel bad, do it! Journal of Personality and Social Psychology, 80, 53-67.

Torrance, E. P., \& Ball, O. E. (1984). Torrance Tests of Creative Thinking: Revised manual. Bensenville, IL: Scholastic Testing Services.

Trope, Y., Ferguson, M., \& Raghunatan, R. (2001). Mood as a resource in processing self-relevant information. In J. Forgas (Ed.), Handbook of affect and cognition (pp. 256-274). Mahwah, NJ: Erlbaum.

Trope, Y., Gervey, B., \& Bolger, N. (2003). The role of perceived control in overcoming defensive self-evaluations. Journal of Experimental Social Psychology, 39, 407-419.

Trope, Y., \& Neter, E. (1994). Reconciling competing motives in selfevaluation: The role of self-control in feedback seeking. Journal of Personality and Social Psychology, 66, 646-657.

Wallach, M. A., \& Kogan, N. (1965). Modes of thinking in young children: A study of the creativity-intelligence distinction. New York: Holt, Rinehart \& Winston.

Wegener, D., \& Petty, R. (1994). Mood management across affective states: The hedonic contingency hypothesis. Journal of Personality and Social Psychology, 66, 1034-1048.

Wegener, D., \& Petty, R. (1996). Effects of mood on persuasion processes: Enhancing, reducing, and biasing scrutiny of attitude-relevant information. In L. L. Martin \& A. Tesser (Eds.), Striving and feeling: Interactions among goals, affect, and self-regulation (pp. 329-362). Hillsdale, NJ: Erlbaum.

Wegener, D., \& Petty, R. (2001). Understanding effects of mood through the elaboration likelihood and flexible correction models. In L. L. Martin \& G. L. Clore (Eds.), Theories of mood and cognition: A user's guidebook (pp. 177-210). Mahwah, NJ: Erlbaum.

Wenzlaff, R., Wegner, D., \& Roper, D. (1988). Depression and mental control: The resurgence of unwanted negative thoughts. Journal of Personality and Social Psychology, 55, 882-892.

Worth, L. T., \& Mackie, D. M. (1987). Cognitive mediation of positive mood in persuasion. Social Cognition, 5, 76-94.

Zillmann, D. (1988). Mood management: Using entertainment to full advantage. In L. Donohew, J. Bryant, \& D. Zillmann (Eds.), Coтmunication, social cognition, and affect (pp. 147-172). Hillsdale, NJ: Erlbaum.

Ziskin, L. (Producer), \& Marshall, G. (Director). (1990). Pretty Woman [Motion picture]. United States: Silver Screen Partners IV.

Zuckerman, M., \& Lubin, B. (1985). Manual for the Multiple Affect Adjective Check List (2nd ed.). San Diego, CA: Educational and Industrial Testing Service. 